\title{
Early reoperations in chronic subdural hematoma
}

\author{
Corresponding author: \\ Borys M. Kwinta, MD, PhD \\ Department of Neurosurgery \\ and Neurotraumatology, \\ Jagiellonian University Medical College \\ Botaniczna 3 street, 31-503, Kraków \\ Poland \\ e-mail: bmkwinta@gmail.com
}

Medical Research Journal 2018;

Volume 3, Number 2, 76-81

10.5603/MRJ.2018.0013

Copyright (C) 2018 Via Medica

ISSN 2451-2591

\begin{abstract}
Background: The recurrence rate of chronic subdural hematoma (cSDH) is high and early reoperation is often required.

Aim: The aim of this study was to evaluate prognostic factors for early reoperation of chronic subdural hematomas $(\mathrm{CSDH})$ treated by classical and minimally invasive approach.

Materials and Methods: We retrospectively analyzed the medical history of $355 \mathrm{cSDH}$ patients treated with formal craniotomy and minimally invasive burr hole craniostomy. We determined the potential predictors of early reoperations.

Results: A total of 33 (9.3\%) patients required early reoperation. Those patients more often underwent craniotomies instead of burr hole craniostomies (36.4\% vs. $62.7 \%, p<0.01$ ) and took steroids before hospitalization (3.0\% vs. $0.3 \%, p=0.04$ ) than non-reoperated patients. Patients who had surgery on the right side were less likely to be reoperated $(51.9 \%$ vs. 33.3\%, $\mathrm{p}=0.04)$. On multivariate analysis the frontal $(\mathrm{OR}=5.284,95 \% \mathrm{Cl}: 1.293-21.76$, $\mathrm{p}=0.019)$ and large craniotomy $(\mathrm{OR}=2.297,95 \% \mathrm{Cl}: 1.004-5.258, \mathrm{p}=0.048)$ remained independent risk factors for early reoperation of $\mathrm{cSDH}$.

Conclusions: Neurosurgeons should consider the evacuation of a cSDH with help of minimally invasive burr hole craniostomy in most of the cases, as well as avoid large and frontal and craniotomies in order to prevent early reoperation of $\mathrm{cSDH}$
\end{abstract}

Key words: reoperation, minimally invasive approach, chronic subdural hematoma, burr hole, craniotomy Med Res J 2018; 3 (2): 76-81

\section{Introduction}

Chronic subdural hematoma (cSDH) is a common problem in neurosurgical practice, which accounts for about $10 \%$ of all intracranial hematomas [1]. It occurs typically in older patients [2-3] and its incidence varies between 1.72 and 20.6 per 100.000 individuals per year [2]. It is usually caused by traumatic event [4]. Initial management of $\mathrm{CSDH}$ remains controversial and might be either conservative or surgical [5-6]. In terms of surgical treatment, there are two main techniques in use. First of them is the group of minimally invasive methods of burr hole craniostomy and twist-drill craniostomy [7]. Alternatively regular craniotomy is performed which, if necessary, might be accompanied by membranectomy [8]. Among surgically treated patients, about $52 \%$ to $77 \%$ result with good functional outcome $[5,9-11]$ and 3-month mortality rate is reported between $8 \%$ and $22 \%$ $[10,12-13]$. One of the predictors of poor treatment outcome is cSDH recurrence $[3,14]$. The rate of this phenomenon is very diverse among different studies and varies between 10 and 33\% [15-17]. Potential predictors of CSDH recurrence have been widely analyzed by other researchers and many factors were identified. The most common was age, bilateral cSDH, anticoagulants intake and approach related complications [18-22]. On the other hand most of authors analyze total recurrence rate regardless of the time period, neglecting early, acute reoperations of cSDH. Predictors of early reoperations by means of reoperation during the same hospitalization are still unknown. Therefore, we decided to analyze which factors might be associated with conditions leading to early reoperations in cSDH treatment with emphasis on minimally invasive techniques.

\section{Materials and Methods}

We retrospectively analyzed 355 patients hospitalized between January 2013 and December 2016 with CT-confirmed CSDH who underwent surgical procedures. Upon admission patients were assessed using 
Glasgow Coma Scale (GCS). From their medical record we obtained detailed medical history which included previous diseases and current medications. We also obtained blood test results taken within 24 hours before the surgery together with details concerning operation such as its date, type and side and whether the doctor who performed the surgery and their assistant were specialists in neurosurgery.

If the patient was qualified for minimally invasive procedure, the two burr hole surgery with saline irrigation and subdural or subperiosteal drain was performed. Closed drainage system was left for 72 hours. The choice of drain compartment was based on personal surgeon decision depending on the width of the subdural space.

Patients with large, nonhomogenous hematoma with membranes were qualified for craniotomy with membranectomy. A typical Redon drainage was placed in craniotomized patients in subperiosteal space. Type of craniotomy was defined by anatomical localization and surface area. Surface area was defined by number of convexity bones that were contained in craniotomy.

Early reoperation was defined as reoperation that occurred during the same hospitalization due to a primary neurosurgical condition.

Study protocol was approved by local University Ethical Committee (protocol number KBET/152/B/2012). All subjects signed an informed consent form.

To perform the statistical analysis, we used $\chi 2$ test for proportional values and t-student test and Mann-Whitney $U$ test as appropriate for continuous variables. To determine the potential predictors of reoperation after cSDH operation we used univariate and multivariate logistic regression analysis. $\mathrm{P}$-values $<0.05$ were considered to be statistically significant. Threshold of p-value $<0.1$ was used to qualify date to multivariate logistic regression analysis. Forward logistic regression analysis was followed by backwards logistic regression analysis. To perform all statistical analysis we used STATISTICA v. 10 for Windows (Statsoft, Poland).

\section{Results}

Our study group consisted of 355 patients and $94(26.47 \%)$ of them were females. Mean age of study group was $70.22 \pm 15.61$ years and mean GCS upon admission was $13.14 \pm 3.62$. A total of $33(9.29 \%)$ underwent early reoperation. The indication for revision surgery was hematoma reaccumulation with or without neurological deterioration or incomplete removal with persisting clinical and radiological signs of mass effect. For revision surgery craniotomy was performed.

Details concerning medical history, current medications and blood test results are presented in Tab. 1.
Reoperated patients significantly less often underwent minimally invasive procedures (burr hole with subdural or subperiosteal drainage) (36.36\% vs. $62.73 \%$; $\mathrm{p}<0.01)$. They also less often had surgery on the right side (33.33 vs. $51.86 \% ; p=0.04$ ). Reoperated patients more often took steroids ( $3.03 \%$ vs. $0.31 \%$; $p=0.04$ ) prior to surgery. The also more often underwent primary surgery with assisting specialist (24.24\% vs. 9.32\%; $\mathrm{p}<0.01)$. Details concerning surgery are presented in Tab. 2. Distribution of type of surgery is presented in Figure 1.

After adjustment for possible confounders, classical approaches like frontal craniotomy (OR: 5.284; 95\% Cl: 1.293-21.576; $p=0.019)$ and fronto-temporo-parietal craniotomy (OR: 2.297; 95\% Cl: 1.004-5.258; $p=0.048$ ) remained independently associated with higher risk of early unplanned reoperation. Minimally invasive approach via burr holes (OR: $0.365 ; 95 \% \mathrm{Cl}$ : $0.172-0.774 ; p<0.01$ ) remained independently associated with lower risk of early unplanned reoperation. Results of multivariate logistic regression analysis are presented in Tab. 3.

\section{Discussion}

We established cSDH early reoperation rate at around $9 \%$ in entire group of patients. Similar rates were observed by Yamamoto et al. and Lee et al. [18-19]. Jung et al. observed recurrence of cSDH in about $13 \%$ of patients included in their study [22] and Torihashi in about $17 \%$ [17]. In their review of 48 studies, Weigel et al. established that $\mathrm{CSDH}$ recurrence rate varied between 10 and $33 \%$ [15].

In our study we determined the impact of minimally invasive approach on reoperation rate in treatment of $\mathrm{cSDH}$. Burr hole craniostomy instead of conventional craniotomy were independently associated with a lower risk of $\mathrm{cSDH}$ recurrence. On the contrary, our study showed independent association between higher risk of cSDH early reoperations and large (fronto-temporo-parietal) or frontal craniotomy. Hematomas demanding wide craniotomy usually are larger and contain thickened or calcified membranes [23]. Furthermore larger craniotomy put the patients at higher risk of surgical complications: cortical injury, intracerebral hemorrhage, seizures, surgical site infection, significant blood loss $[17,20,23]$. Similar association had been observed in Schulz et al. study [24]. Also, in Weigel et al. study, morbidity was higher for patients who underwent craniotomies [15]. This is in comparison to the Hamilton et al. study, in which they found no differences between these surgical techniques in terms of cSDH recurrence [25]. Craniotomy (12.3\%) has a higher morbidity comparing to minimally invasive approaches like burr hole 
Table 1. Details concerning medical history, medications and blood test results in reoperated and non-reoperated group

\begin{tabular}{|c|c|c|c|}
\hline & Reoperation (n = 33) & No reoperation $(n=322)$ & p-value \\
\hline Age [years] $\pm S D$ & $68.27 \pm 17.69$ & $70.42 \pm 15.4$ & 0.45 \\
\hline Glasgow Coma Scale \pm SD & $13.50 \pm 3.21$ & $13.10 \pm 3.67$ & 0.72 \\
\hline Female gender [\%] & 30.3 & 26.09 & 0.60 \\
\hline \multicolumn{4}{|l|}{ Medical history } \\
\hline Hypertension [\%] & 39.39 & 31.37 & 0.35 \\
\hline Diabetes mellitus [\%] & 9.09 & 16.77 & 0.25 \\
\hline Cigarette smoking [\%] & 21.21 & 12.42 & 0.16 \\
\hline Alcohol abuse [\%] & 12.12 & 21.74 & 0.19 \\
\hline Ischemic heart disease [\%] & 9.09 & 2.8 & 0.056 \\
\hline History of heart attack [\%] & 6.06 & 4.97 & 0.79 \\
\hline History of ischemic stroke [\%] & 6.06 & 6.52 & 0.92 \\
\hline Atrial fibrillation [\%] & 9.09 & 12.11 & 0.61 \\
\hline Lungs diseases [\%] & 3.03 & 1.86 & 0.65 \\
\hline Hyperthyroidism [\%] & 0 & 0.62 & 0.65 \\
\hline Hypothyroidism [\%] & 0 & 3.73 & 0.26 \\
\hline Hypercholesterolemia [\%] & 0 & 4.97 & 0.19 \\
\hline \multicolumn{4}{|l|}{ Current medications } \\
\hline Acetylsalicylic acid [\%] & 6.06 & 7.14 & 0.82 \\
\hline Beta-blockers [\%] & 12.12 & 13.04 & 0.88 \\
\hline Angiotensin-converting-enzyme inhibitors [\%] & 15.15 & 11.80 & 0.57 \\
\hline $\mathrm{AT}_{2}$-blockers [\%] & 0 & 1.24 & 0.52 \\
\hline Calcium channel blockers [\%] & 3.03 & 5.9 & 0.49 \\
\hline Diuretics [\%] & 12.12 & 15.22 & 0.63 \\
\hline Steroids [\%] & 3.03 & 0.31 & 0.04 \\
\hline Antidiabetic therapy [\%] & 0 & 4.66 & 0.21 \\
\hline Insulin [\%] & 6.06 & 5.28 & 0.85 \\
\hline Heparin [\%] & 0 & 1.55 & 0.47 \\
\hline Anticoagulants [\%] & 6.06 & 11.49 & 0.34 \\
\hline Nitrates [\%] & 0 & 2.80 & 0.33 \\
\hline Statins [\%] & 0 & 3.73 & 0.26 \\
\hline \multicolumn{4}{|l|}{ Blood test results preceding surgery } \\
\hline Red Blood Cells count $\left[10^{3} / \mu l\right] \pm$ SD & $3.97 \pm 0.73$ & $3.96 \pm 0.68$ & 0.93 \\
\hline White Blood Cells count $\left[10^{3} / \mu l\right] \pm$ SD & $9.80 \pm 4.40$ & $9.19 \pm 4.10$ & 0.46 \\
\hline Platelets count $\left[10^{3} / \mu \mathrm{l}\right] \pm \mathrm{SD}$ & $216.04 \pm 80.19$ & $225.84 \pm 94.11$ & 0.60 \\
\hline Activated Partial Prothrombin Time $[\mathrm{s}] \pm \mathrm{SD}$ & $12.13 \pm 1.95$ & $12.01 \pm 1.98$ & 0.77 \\
\hline International Normalized Ratio \pm SD & $29.28 \pm 4.36$ & $33.2 \pm 8.72$ & 0.08 \\
\hline Creatinine $[\mu \mathrm{mol} / /] \pm \mathrm{SD}$ & $1.11 \pm 0.13$ & $1.34 \pm 0.71$ & 0.12 \\
\hline Glucose $[\mathrm{mmol} / \mathrm{l}] \pm \mathrm{SD}$ & $83.32 \pm 68.17$ & $80.34 \pm 36.5$ & 0.74 \\
\hline Mean Corpuscular Volume $\left[\mu \mathrm{m}^{3}\right] \pm \mathrm{SD}$ & $5.6 \pm 1.6$ & $7.41 \pm 14.41$ & 0.56 \\
\hline Mean Corpuscular Hemoglobin [pg] \pm SD & $90.57 \pm 9.70$ & $90.02 \pm 5.42$ & 0.65 \\
\hline Mean Corpuscular Hemoglobin Concentration $[\mathrm{g} / \mathrm{dl}] \pm \mathrm{SD}$ & $30.82 \pm 3.16$ & $30.43 \pm 2.09$ & 0.39 \\
\hline Urea $[\mathrm{mmol} / \mathrm{l}] \pm \mathrm{SD}$ & $34.06 \pm 1.41$ & $33.8 \pm 1.24$ & 0.31 \\
\hline Sodium $[\mathrm{mmol} / \mathrm{l}] \pm \mathrm{SD}$ & $7.13 \pm 6.93$ & $6.83 \pm 4.58$ & 0.78 \\
\hline Potassium $[\mathrm{mmol} / \mathrm{l}] \pm \mathrm{SD}$ & $140.12 \pm 3.05$ & $139.24 \pm 4.70$ & 0.36 \\
\hline Prothrombin Time $[\mathrm{s}] \pm \mathrm{SD}$ & $4.03 \pm 0.59$ & $4.12 \pm 0.56$ & 0.46 \\
\hline Hematocrit [\%] \pm SD & $12.32 \pm 0.92$ & $14.64 \pm 6.70$ & 0.16 \\
\hline
\end{tabular}


Table 2. Details of surgery in reoperated and non-reoperated patients

\begin{tabular}{lccc}
\hline & $\begin{array}{c}\text { Reoperation } \\
\text { (n= 33) }\end{array}$ & $\begin{array}{c}\text { No reoperation } \\
\text { (n= 322) }\end{array}$ & p-value \\
\hline Surgery during weekend [\%] & 24.24 & 32.61 & 0.33 \\
"On call" hours of surgery [\%] & 30.30 & 27.64 & 0.75 \\
Bone flap removal [\%] & 75.76 & 84.78 & 0.17 \\
Operating specialist & 33.33 & 37.27 & 0.66 \\
Assisting specialist & 24.24 & 9.32 & 0.01 \\
Approach & & & 0.07 \\
Fronto-temporo-parietal [\%] & 30.3 & 17.39 & 0.78 \\
Fronto-parietal [\%] & 3.03 & 4.04 & 0.75 \\
Parieto-occipital [\%] & 0 & 0.31 & 0.75 \\
Temporal [\%] & 0 & 0.31 & 0.30 \\
Parietal [\%] & 6.06 & 2.80 & 0.056 \\
Frontal [\%] & 9.09 & 2.80 & $<0.01$ \\
Minimally invasive burr hole craniostomy [\%] & 36.36 & 62.73 & 0.04 \\
Right side [\%] & 33.33 & 51.86 & 0.31 \\
Left side [\%] & 63.64 & 54.35 & \\
\hline
\end{tabular}

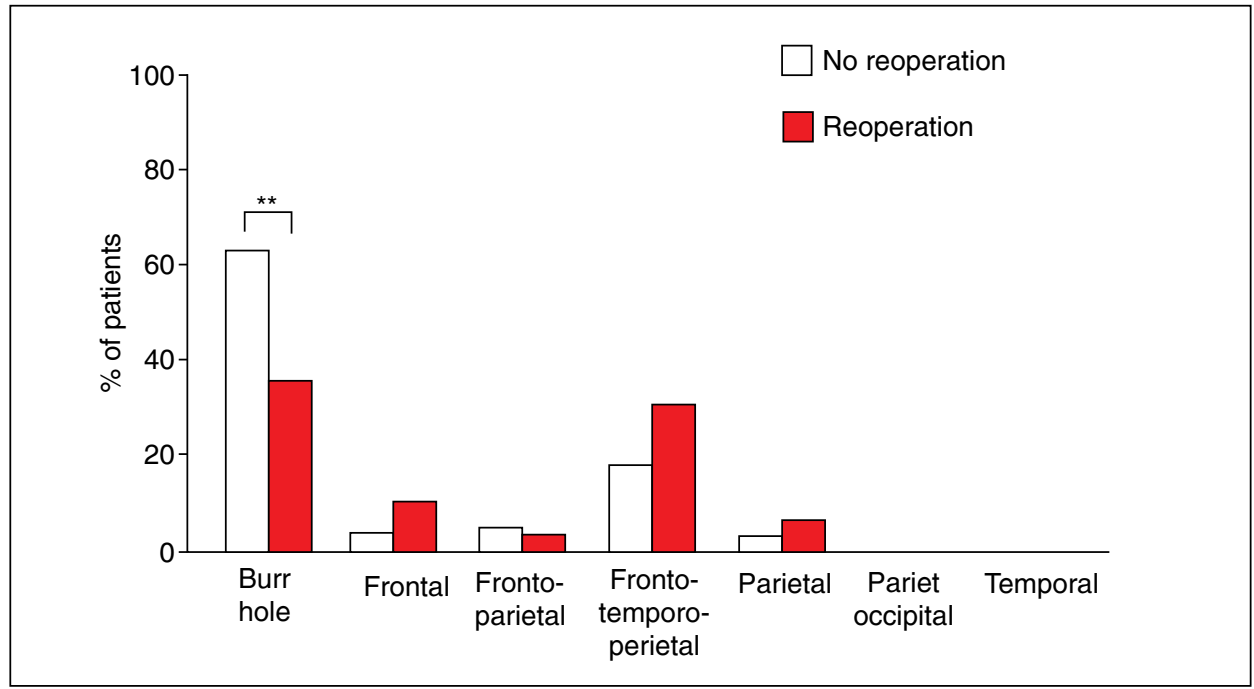

Figure 1. Distribution of type of surgery in reoperated and non-reoperated group; ${ }^{* *}-p$-value $<0.01$

Table 3. Results of multivariate logistic regression analysis. OR - Odds Ratio, $\mathrm{Cl}$ - Confidence Interval

\begin{tabular}{lccc}
\hline Risk factor & OR & $\mathbf{9 5 \%} \mathbf{~ C l}$ & p-value \\
\hline Frontal craniotomy & 5.284 & $1.293-21.576$ & 0.019 \\
Fronto-temporo-parietal craniotomy & 2.297 & $1.004-5.258$ & 0.048 \\
Minimally invasive burr hole craniostomy & 0.365 & $0.172-0.774$ & $<0.01$ \\
Assisting specialist & 3.433 & $1.389-8.489$ & $<0.01$ \\
\hline
\end{tabular}


(3.8\%) and twist drill craniostomy (3.0\%) but similar cure and mortality rates [15]. The fact that burr hole surgery carries lower risk of complications can be explained by the fact that this procedure is much less invasive and also easier to perform than a craniotomy. Association between less invasive procedure and lower risk of recurrence can also be proved by Taussky et al. study which showed that the number of burr holes can be an independent risk factor of cSDH recurrence [26].

While surgery is a gold standard for treating $\mathrm{cSDH}$, than burr hole is the most commonly performed approach to treat it. Although there is no class I evidence showing which technique is superior, and the decision is based mainly on the house rules the burr hole technique remains the best option for treating $\mathrm{cSDH}$. This proposal results from its beneficial cure to complications ratio. Although twist drill craniostomy is often performed as bedside intervention with only local anesthesia the higher risk of infection is an important issue to consider. [23]

The recurrence rate of burr hole craniostomy $(11.7 \%)$ is much lower than craniotomy $(19.4 \%)$ and another minimally invasive technique, twist drill craniostomy (28.1\%) as showed Ducruet et al. study [27].

The lower recurrence rate was shown to be achieved when the drainage system was used as a part of burr hole craniostomy procedure [28]. This may also correspond to lower risk of early reoperation while using this minimally invasive technique in our study. Furthermore to reduce the cortical surface injury the drain was inserted subdurally only in case if it was judged as safe, otherwise was placed in subperiosteal space. The safe use of extracranial drain was proofed by Yadav et al [29].

An interesting finding of our study was independent association between right side $\mathrm{CSDH}$ and lower risk of its early recurrence needing reoperation. Influence of cSDH side on recurrence rate had been analyzed before by a few researchers [16-17, 29-30]. However, none of them found any significant correlation in terms of this predictor. Only bilateral cSDH was proved to be associated with higher risk of recurrence [16, 21]. Chen et al. in their study suggested that $\mathrm{CSDH}$ on the left side might increase the risk of post-operative seizures [30]. As seizures were proved to be an independent risk factor of $\mathrm{cSDH}$ recurrence by Kong et al., these facts might explain abovementioned correlation [31].

We also discovered association between preoperative chronic steroids intake and early cSDH recurrence. Influence of steroids intake had been analyzed before in terms of cSDH recurrence [16], as corticosteroids treatment had been considered as therapy for both alternative and adjuvant to surgical treatment of $\mathrm{cSDH}$ [4]. Few researchers have found no association between $\mathrm{CSDH}$ recurrence and steroids intake [32-34]; however, in their meta-analysis Almenawer et al. found that steroids treatment adjuvant to surgical treatment was associated with higher mortality among patients with cSDH [4]. This might be consistent with our results.

Our study was limited by fact that obtained data come from single neurosurgical facility experience. Further research should be performed as multi-center study. Despite those limitations, we were able to analyze possible complications requiring early reoperation after chronic subdural hematoma surgeries during 4-year period.

\section{Conclusions}

Factors such as frontal craniotomy, fronto-temporo-parietal craniotomy, previous steroids intake and assisting specialist can be associated with a higher risk of early cSDH recurrence needing reoperation and should be taken into consideration while planning treatment of patients with $\mathrm{cSDH}$ and during postoperative care. On the other hand, patients who undergo minimally invasive procedures instead of craniotomies and surgery on the right side due to $\mathrm{cSDH}$ treatment are at lower risk of early reoperation.

\section{References}

1. Wan Yi, Fei X, Jiang D, et al. Clinical Observation of Treatment of Chronic Subdural Hematoma With Novel Double Needle Minimally Invasive Aspiration Technology. J Craniofac Surg. 2017; 28(3): 646-649, doi: 10.1097/SCS.0000000000003462, indexed in Pubmed: 28468141.

2. Yang W, Huang J. Chronic Subdural Hematoma: Epidemiology and Natural History. Neurosurg Clin N Am. 2017; 28(2): 205-210, doi: 10.1016/j.nec.2016.11.002, indexed in Pubmed: 28325454.

3. Toi H, Kinoshita K, Hirai S, et al. Present epidemiology of chronic subdural hematoma in Japan: analysis of 63,358 cases recorded in a national administrative database. J Neurosurg. 2018; 128(1): 222-228, doi: 10.3171/2016.9.JNS16623, indexed in Pubmed: 28156246.

4. Almenawer SA, Farrokhyar F, Hong C, et al. Chronic subdural hematoma management: a systematic review and meta-analysis of 34,829 patients. Ann Surg. 2014; 259(3): 449-457, doi: 10.1097/SLA.0000000000000255, indexed in Pubmed: 24096761.

5. Brennan PM, Kolias AG, Joannides AJ, et al. British Neurosurgical Trainee Research Collaborative, British Neurosurgical Trainee Research Collaborative. The management and outcome for patients with chronic subdural hematoma: a prospective, multicenter, observational cohort study in the United Kingdom. J Neurosurg. 2017; 127(4): 732-739, doi: 10.3171/2016.8.JNS16134, indexed in Pubmed: 27834599

6. Soleman J, Nocera F, Mariani L. The conservative and pharmacological management of chronic subdural haematoma. Swiss Med Wkly. 2017; 147: w14398, doi: 10.4414/smw.2017.14398, indexed in Pubmed: 28102879.

7. Jablawi F, Kweider H, Nikoubashman O, et al. Twist Drill Procedure for Chronic Subdural Hematoma Evacuation: An Analysis of Predictors for Treatment Success. World Neurosurg. 2017; 100: 480-486, doi: 10.1016/j.wneu.2017.01.037, indexed in Pubmed: 28109862.

8. Sahyouni R, Mahboubi H, Tran P, et al. Membranectomy in Chronic Subdural Hematoma: Meta-Analysis. World Neurosurg. 2017; 104: 418-429, doi: 10.1016/j.wneu.2017.05.030, indexed in Pubmed: 28512051.

9. Ro HW, Park SK, Jang DK, et al. Preoperative predictive factors for surgical and functional outcomes in chronic subdural hematoma. Acta Neurochir (Wien). 2016; 158(1): 135-139, doi: 10.1007/s00701-0152625-z, indexed in Pubmed: 26602235

10. Weimer JM, Gordon E, Frontera JA. Predictors of Functional Outcome After Subdural Hematoma: A Prospective Study. Neurocrit Care. 2017; 26(1): 70-79, doi: 10.1007/s12028-016-0279-1, indexed in Pubmed: 27230968. 
11. Toi H, Kinoshita K, Hirai S, et al. Present epidemiology of chronic subdural hematoma in Japan: analysis of 63,358 cases recorded in a national administrative database. J Neurosurg. 2018; 128(1): 222-228, doi: 10.3171/2016.9.JNS16623, indexed in Pubmed: 28156246.

12. Lukasiewicz AM, Grant RA, Basques BA, et al. Patient factors associated with 30-day morbidity, mortality, and length of stay after surgery for subdural hematoma: a study of the American College of Surgeons National Surgical Quality Improvement Program. J Neurosurg. 2016; 124(3): 760-766, doi: 10.3171/2015.2.JNS142721, indexed in Pubmed: 26315000.

13. Manickam A, Marshman LAG, Johnston R. Long-term survival after chronic subdural haematoma. J Clin Neurosci. 2016; 34: 100-104, doi: 10.1016/j.jocn.2016.05.026, indexed in Pubmed: 27460457.

14. Han $\mathrm{MH}$, Ryu Jell, $\mathrm{Kim} \mathrm{CH}$, et al. Predictive factors for recurrence and clinical outcomes in patients with chronic subdural hematoma. Neurosurg. 2017; 127(5): 1117-1125, doi: 10.3171/2016.8.JNS16867, indexed in Pubmed: 27982768.

15. Weigel R, Schmiedek P, Krauss JK. Outcome of contemporary surgery for chronic subdural haematoma: evidence based review. J Neurol Neurosurg Psychiatry. 2003; 74(7): 937-943, indexed in Pubmed: 12810784.

16. Oh HJ, Lee KS, Shim JJ, et al. Postoperative course and recurrence of chronic subdural hematoma. J Korean Neurosurg Soc. 2010 48(6): 518-523, doi: 10.3340/jkns.2010.48.6.518, indexed in Pubmed: 21430978

17. Torihashi K, Sadamasa N, Yoshida K, et al. Independent predictors for recurrence of chronic subdural hematoma: a review of 343 consecutive surgical cases. Neurosurgery. 2008; 63(6): 1125-9; discussion 1129 doi: 10.1227/01.NEU.0000335782.60059.17, indexed in Pubmed 19008766.

18. Yamamoto $\mathrm{H}$, Hirashima $\mathrm{Y}, \mathrm{Hamada} \mathrm{H}$, et al. Independent predictors of recurrence of chronic subdural hematoma: results of multivariate analysis performed using a logistic regression model. J Neurosurg. 2003; 98(6): 1217-1221, doi: 10.3171/jns.2003.98.6.1217, indexed in Pubmed: 12816267

19. Lee J, Park J, Kim J. Retrospective Analysis of Risk Factors for Recurrent Chronic Subdural Hematoma. The Nerve. 2016; 2(2): 54-58, doi: 10.21129/nerve.2016.2.2.54

20. Song DH, Kim YS, Chun HJ, et al. The Predicting Factors for Recurrence of Chronic Subdural Hematoma Treated with Burr Hole and Drainage. Korean J Neurotrauma. 2014; 10(2): 41-48, doi: 10.13004/kjnt.2014.10.2.41, indexed in Pubmed: 27169032

21. Santarius T, Kirkpatrick PJ, Ganesan D, et al. Use of drains versus no drains after burr-hole evacuation of chronic subdural haematoma: a randomised controlled trial. Lancet. 2009; 374(9695): 1067-1073, doi: 10.1016/S0140-6736(09)61115-6, indexed in Pubmed: 19782872

22. Jung YG, Jung NY, Kim El. Independent predictors for recurrence of chronic subdural hematoma. J Korean Neurosurg Soc. 2015; 57(4):
266-270, doi: 10.3340/jkns.2015.57.4.266, indexed in Pubmed: 25932293

23. Buchanan IA, Mack WJ. Minimally Invasive Surgical Approaches for Chronic Subdural Hematomas. Neurosurg Clin N Am. 2017; 28(2): 219-227, doi: 10.1016/j.nec.2016.11.004, indexed in Pubmed: 28325456 .

24. Schulz W, Saballus R, Flügel R, et al. [Chronic subdural hematoma. A comparison of bore hole trepanation and craniotomy]. Zentralbl Neurochir. 1988; 49(4): 280-289, indexed in Pubmed: 3252645.

25. Hamilton MG, Frizzell JB, Tranmer BI. Chronic subdural hematoma: the role for craniotomy reevaluated. Neurosurgery. 1993; 33(1): 67-72, indexed in Pubmed: 8355849

26. Taussky P, Fandino J, Landolt $H$. Number of burr holes as independent predictor of postoperative recurrence in chronic subdural haematoma. Br J Neurosurg. 2008; 22(2): 279-282, doi: 10.1080/02688690701818885, indexed in Pubmed: 18348026.

27. Ducruet AF, Grobelny BT, Zacharia BE, et al. The surgical management of chronic subdural hematoma. Neurosurg Rev. 2012; 35(2): 155-69; discussion 169, doi: 10.1007/s10143-011-0349-y, indexed in Pubmed: 21909694.

28. Yadav YR, Parihar $\mathrm{V}$ Chourasia ID, et al. The role of subgaleal suction drain placement in chronic subdural hematoma evacuation. Asian J Neurosurg. 2016; 11(3): 214-218, doi: 10.4103/1793-5482.145096, indexed in Pubmed: 27366247.

29. Mori K, Maeda M. Surgical treatment of chronic subdural hematoma in 500 consecutive cases: clinical characteristics, surgical outcome, complications, and recurrence rate. Neurol Med Chir (Tokyo). 2001; 41(8): 371-381, indexed in Pubmed: 11561347.

30. Chen CW, Kuo JR, Lin HJ, et al. Early post-operative seizures after burr-hole drainage for chronic subdural hematoma: correlation with brain CT findings. J Clin Neurosci. 2004; 11(7): 706-709, doi: 10.1016/i . jocn.2004.03.019, indexed in Pubmed: 15337129.

31. Kong WK, Kim BC, Cho KT, et al. Factors Affecting Postoperative Recurrence of Chronic Subdural Hematoma. Korean Journal of Neurotrauma. 2012; 8(2): 122, doi: 10.13004/kjnt.2012.8.2.122.

32. Dran G, Berthier F, Fontaine D, et al. [Effectiveness of adjuvant corticosteroid therapy for chronic subdural hematoma: a retrospective study of 198 cases]. Neurochirurgie. 2007; 53(6): 477-482, doi: 10.1016/j. neuchi.2007.09.146, indexed in Pubmed: 18061628

33. Berghauser Pont LME, Dammers R, Schouten JW et al Clinical factors associated with outcome in chronic subdural hematoma: a retrospective cohort study of patients on preoperative corticosteroid therapy. Neurosurgery. 2012; 70(4): 873-80; discussion 880, doi: 10.1227/NEU.0b013e31823672ad, indexed in Pubmed: 21937933.

34. Berghauser Pont LME, Dirven CMF, Dippel DWJ, et al. The role of corticosteroids in the management of chronic subdural hematoma: a systematic review. Eur J Neurol. 2012; 19(11): 1397-1403, doi: 10.1111/j.1468-1331.2012.03768.x, indexed in Pubmed: 22642223. 